\title{
Production and Characterisation of Aluminium Alloy - Bagasse Ash Composites
}

\author{
A. M. Usman*, A. Raji, N. H. Waziri and M. A. Hassan \\ Mechanical Engineering Department, Modibbo Adama University of Technology, Yola,AdamawaState, Nigeria
}

\begin{abstract}
The study was carried out to determine the density and mechanical properties of Al-7\%Si alloy Bagasse Ash (BA) composite produced at $800^{\circ} \mathrm{C}$. BA obtained at $700^{\circ} \mathrm{C}$ and having high silica and alumina contents of up to $77.29 \%$ and $10.95 \%$, respectively was used as reinforcement and varied from $0 v 0 l \%$ to $30 \mathrm{vol} \%$. The density and some mechanical properties of the produced composites were determined. The results showed that the density decreases with percentage increase in reinforcement from $2840.242 \mathrm{kgm}^{-3}$ to $2292.208 \mathrm{kgm}^{-3}$ with the minimum value at $30 \mathrm{vol} \%$ BA. The results of the mechanical properties tests showed that, the ultimate tensile strength (UTS) varies from $139.677 \mathrm{MNm}^{-2}$ to $176.683 \mathrm{MNm}^{-2}$ with maximum value at $10 \mathrm{vol} \% \mathrm{BA}$, Young modulus varies from $1429.890 \mathrm{MNm}^{-2}$ to $1725.425 \mathrm{MNm}^{-2}$ with maximum value at $10 \mathrm{vol} \% \mathrm{BA}$, impact strength varies from $75.401 \mathrm{kJm}^{-2}$ to $128.262 \mathrm{kJm}^{-2}$ with maximum value at $10 \mathrm{vol} \%$ BA and hardness varies from $70.467 R H V$ to $90.767 H R V$ with maximum value at $20 \mathrm{vol} \%$ BA and with all the hardness values better than that of the control sample. The results also showed that, the fatigue strength varies from $0.066 \times 10^{6}$ cycles to $1.797 \times 10^{6}$ cycles with maximum value at $15 \mathrm{vol} \%$ BA and the percentage elongation having approximately the same value.The results of the statistical analysis showed that there are significant differences among the means of each property of the composites at various levels of BA replacement $(P<0.05)$.It was concluded that bagasse ash can be used as reinforcement in aluminium composites and the produced composites could be used in automobile industry for the production of engine blocks, pistons, among others.

Keywords: Alumina, Aluminium Alloy, Bagasse Ash, Composite, Density, Mechanical Properties and Silica.
\end{abstract}

\section{Introduction}

Aluminium is widely used as a structural material especially in the aerospace industry because of its light weight property. However, the low strength and low melting point were always a problem. A cheap method of solving these problem was the use of reinforcement elements such as $\mathrm{SiO}_{2}, \mathrm{Al}_{2} \mathrm{O}_{3}, \mathrm{SiC}$ particles and whiskers or other elements or compounds as alloying elements. The addition of these ceramics and alloying elements particles addition make it possible to increase the specific elastic modulus of aluminium, improve its thermal properties etc. Using several methods including powder metallurgy, stiring methods etc to produce aluminium composites and alloys reinforced with particulates and other alloying elements will help to produce a homogenous distribution of reinforcement in matrix [1]. The term "composite" broadly refers to a material system which is composed of a discrete constituent (the reinforcement) distributed in a continuous phase (the matrix), and which derives its distinguishing characteristics from the properties of its constituents, from the geometry and architecture of the constituents, and from the properties of the boundaries (interfaces) between different constituents [2] while according to Surappa [3] and Mallick[4], the matrix is a percolating "soft" phase (which in general has excellent ductility, formability and thermal conductivity) in which are embedded the "hard" reinforcements (characterised by high stiffness and low thermal expansion).

Bagasse is a by-product from the sugar industry and it is usually burnt at the mill to provide process power or steam that provides energy for process machineries. The use of sugar cane bagasse as a source of energy, because of its appreciable calorific value, leads to production of ash as waste which has no specific economic application. A new reuse process of these wastes has to be established because these wastes, their ashes and gases are environmental burdens [5,6]. Reinforcing aluminium metal with bagasse ash as a source of silica and alumina particulate will yield a material that displays combination of physical and mechanical properties of both the metal matrix and the silica. In our previous work [7], sugar cane bagasse from Savannah Sugar Company Numan was burnt at various temperatures to determine the silica and alumina potentials of its ash and it was concluded that bagasse ash obtained at $700^{\circ} \mathrm{C}$ has greater silica and alumina potentials. The aim of this work is to utilise abundant bagasse ash as agricultural wastes in the north eastern region of Nigeria as reinforcement in the production of aluminium matrix composites so as to reduce the environmental impact of the solid wastes to the society and improve economic utilisation of bagasse waste and aluminium matrix composites. 


\subsection{Material Preparation}

\section{Materials and Methods}

Bagasse was obtained from Savannah Sugar Company Numan, Numan Local Government Area of Adamawa state, Nigeria. The bagasse, which was obtained directly from processing unit of the company, was washed and dried in the factory under sun rays. The bagasse was then ashed at $700^{\circ} \mathrm{C}$ for two hours and the chemical composition of the bagasse ash obtained is shown in Table 1 [7]. The ash before use as reinforcement was further burnt at $1100^{\circ} \mathrm{C}$ for another two hours.

The aluminium scraps in form of automobile parts, aluminium sheets, canes and pipes etc. were obtained from scraps dealers in Girei market, Girei Local Government Area of Adamawa state. The scraps were melted together in a crucible for homogeneity and cast into cylindrical ingots. The chemical analysis was carried out using atomic absorption spectrometry. The sample was converted to fine powder and $1 \mathrm{~g}$ of the sample was mixed with $20 \mathrm{~cm}^{3}$ of $3: 1 \mathrm{HCl}$ acid to Nitric acid ratio mixture and $20 \mathrm{~cm}^{3}$ distilled water. The mixture was heated on a hot plate for $1 \mathrm{hr}$ at $90-100^{\circ} \mathrm{C}$ for digestion and filtered to remove impurities. The filterate was further mixed with $100 \mathrm{~cm}^{3}$ of the distilled water and its fraction was put into sample cup and loaded to the machine and the results obtained are shown in Table 2.

Table 1: Chemical Composition of Sugarcane Bagasse Ash Obtained at $700^{\circ} \mathrm{C}$, wt $\%$

\begin{tabular}{cccccccccc}
\hline $\mathrm{SiO}_{2}$ & $\mathrm{Al}_{2} \mathrm{O}_{3}$ & $\mathrm{Fe}_{2} \mathrm{O}_{3}$ & $\mathrm{CaO}$ & $\mathrm{MgO}$ & $\mathrm{SO}_{3}$ & $\mathrm{~K}_{2} \mathrm{O}$ & $\mathrm{Na}_{2} \mathrm{O}$ & Others & LOI \\
\hline 77.29 & 10.95 & 3.66 & 2.09 & 1.49 & 0.49 & 3.16 & 0.38 & Balance & 3.28 \\
\hline
\end{tabular}

Table 2: Elemental Composition of Synthesized Aluminium Alloy, wt \%

\begin{tabular}{ccccccccc}
\hline $\mathrm{Si}$ & $\mathrm{Mn}$ & $\mathrm{Fe}$ & $\mathrm{Cu}$ & $\mathrm{Zn}$ & $\mathrm{Mg}$ & $\mathrm{Cr}$ & $\mathrm{Ti}$ & $\mathrm{Al}$ \\
\hline 6.70 & 0.80 & 1.50 & 3.20 & 0.50 & 0.35 & 0.10 & 0.10 & $\mathrm{Bal}$ \\
\hline
\end{tabular}

\subsection{Composite Production}

The percentage of the ash used to produce the composite was $0-30 \mathrm{vol} \%$ at an interval of $5 \mathrm{vol} \%$ and the samples were labelled as control for $0 \mathrm{vol} \%$ and CBA 1 to CBA 6 for $5 \mathrm{vol} \%-30 \mathrm{vol} \%$. The production was carried out in mild steel container at a temperature of $800 \pm 20^{\circ} \mathrm{C}$ in a metallurgical furnace in the Mechanical Engineering Department, Modibbo Adama University of Technology, Yola. Weighed amount of aluminium ingot was first put into the container and heated in the furnace for one and half hour at a temperature of $800^{\circ} \mathrm{C}$ after which the reinforcement was added followed by stirring for 3-5 minutes. The molten composite was again held in the furnace for another 20 minutes. The molten composite was poured into a pipe mould of length of $30 \mathrm{~cm}$ and diameter of $2.5 \mathrm{~cm}$ and allowed to cool to room temperature. The produced composites were prepared for density, tensile strength, impact strength, hardness and fatigue tests.

\subsection{Testing Procedure}

The density of the composites was determined by finding the mass and the volume of the sample. The mass was determined using weighing electric balance and the volume through Archimedes Principle by immersing the sample into a graduated measuring cylinder and the rise in volume was recorded and used to calculate the densities.

The tensile strength was determined by first preparing the sample, according to Figure 1, on a lathe machine. The sample was then put on a Mosanto Tensometer and loaded to breaking point axially and the reading was taken in the form of graph on a graph paper.

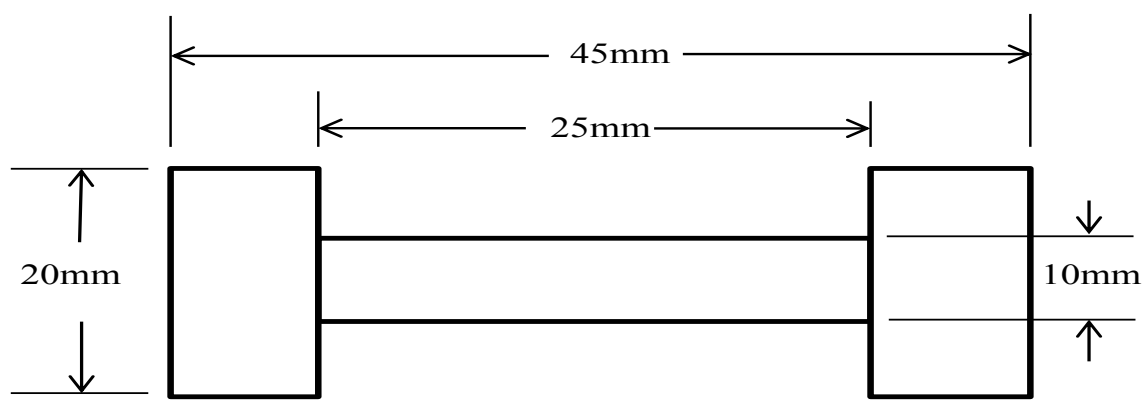

Figure 1: Line Diagram of Tensile Test Specimen

The impact strength was carried out by preparing the sample according to Figure 2, on a lathe machine and tested on a Hounsfield Balanced Impact Strength Testing Machine. The sample was inserted into the notch 
hole and the release lever was released thereby releasing the loading arm and the specimen holder to meet at the bottom where the loading arm impacted on the specimen and the reading was taken from the calibrated scale.

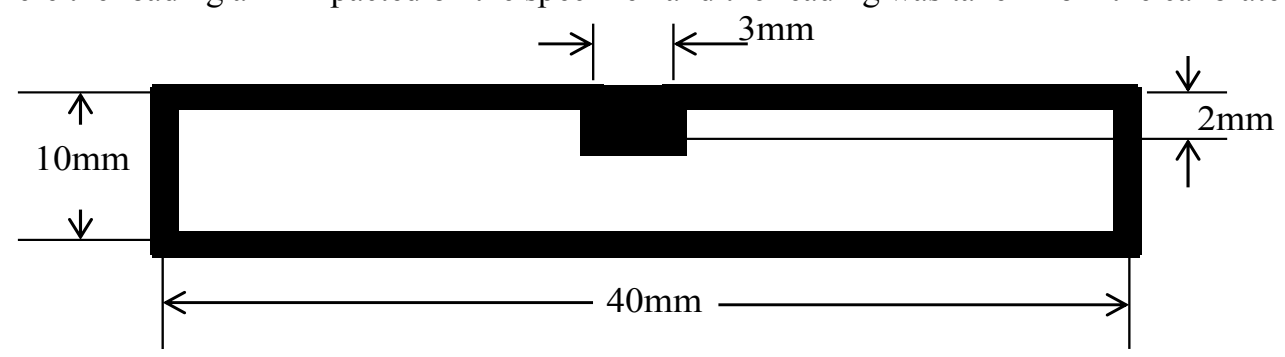

Figure 2: Line Diagram for Impact Strength Test Specimen

The hardness was carried out on an Indentic Rockwell hardness testing machine. The hardnessspecimen was put on the sample position and the indenter of $1 / 16$ " (steel ball) was forced to indent on the specimen. The minor and the total loads of the machine were $10 \mathrm{~kg}$ and $60 \mathrm{~kg}$ respectively.

Fatigue strength was determined by loading the samples with a constant load of $80 \mathrm{~N}$ at end A while the end B was attached to the chuck of the machine and the number of cycles at which the samples failed was determined from the meter on the fatigue testing machine.The schematic diagram of the fatigue strength test specimen is shown in figure 3.

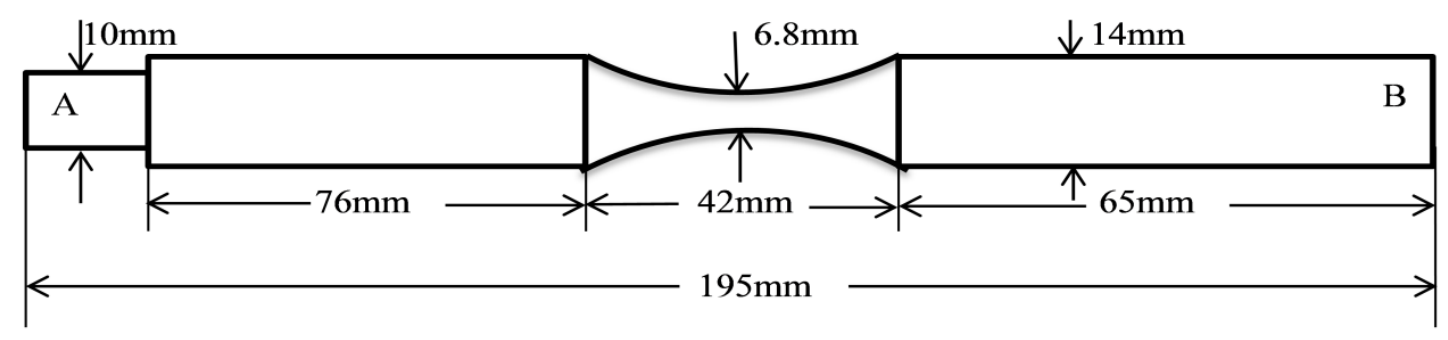

Figure 3: Schematic Diagram for Fatigue Test Specimen

Using SPSS statistical tool software, the variance among the means of all the levels of ash replacement was analysed.

\subsection{Density Measurement}

\section{Results and Discussion} density.

Figure 4 shows the variation of density with bagasse ash (BA) addition and the percentage decrease in

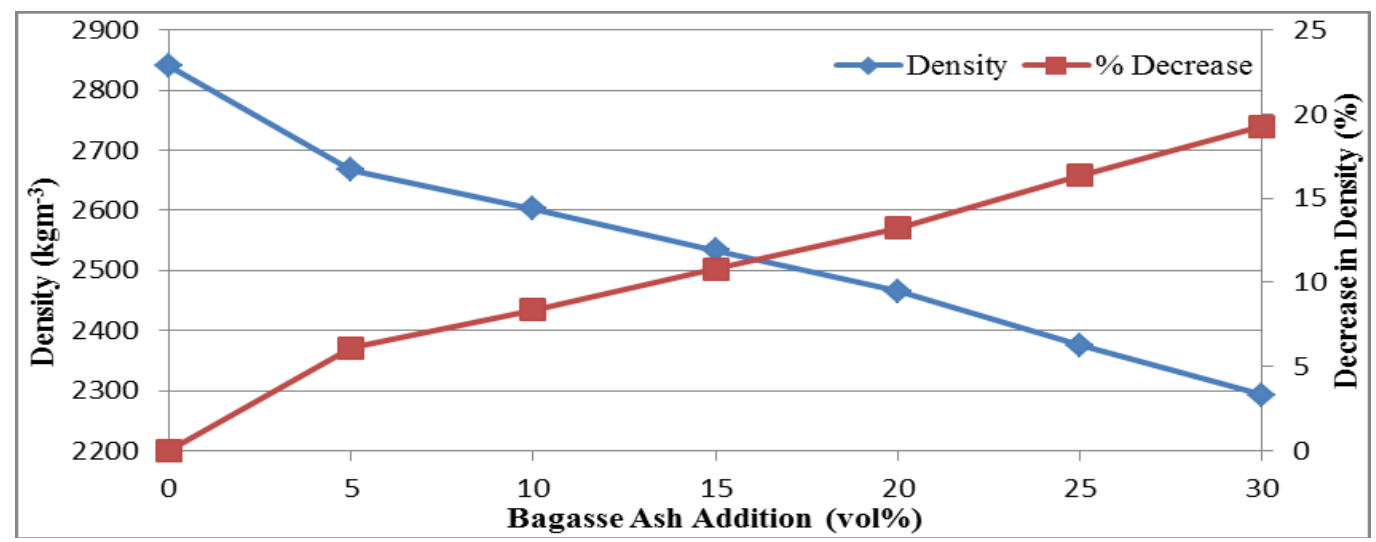

Figure 4: Variation of Densities and Percentage Density Decrease with BA Addition

From Figure 4, it can be observed that the density of the produced composites decreases with the percentage volume of BA addition from $2840.242 \mathrm{kgm}^{-3}$ for the control sample to a minimum of $2292.208 \mathrm{kgm}^{-3}$ at $30 \% \mathrm{BA}$. The decrease in densities is due to addition of low density BA ash of $238.269 \mathrm{kgm}^{-3}$ which leads to 
the replacement of soft and high density matrix material with a hard and low density reinforcement material in the composites thereby giving the composites overall decrease in densities with addition of the ashes. This is in line with results reported by Prasad and Krishna $[8,9]$ who obtained density from $2760 \mathrm{kgm}^{-3}$ to $2570 \mathrm{kgm}^{-3}$ for addition of BA $2 \%-8 \%$, Dhadsanadhep et al. [10] who reported densities of composites with $0-15 \%$ RHA addition from $2700 \mathrm{kgm}^{-3}$ for the control sample to $2120 \mathrm{kgm}^{-3}, 1970 \mathrm{kgm}^{-3}, 2550 \mathrm{kgm}^{-3}$ and $2690 \mathrm{kgm}^{-3}$ for green, sintered, forged and theoretical densities, respectively. Shanmughasundaram et al. [11] reported $2700 \mathrm{kgm}^{-3}-$ $2523 \mathrm{kgm}^{-3}$ for $0-25 \%$ fly ash addition and Zuhailawati et al. [6] used $0-40 \%$ commercial silica and reported $2700 \mathrm{kgm}^{-3}-2679.7 \mathrm{kgm}^{-3}$ theoretical density, $2329.5 \mathrm{kgm}^{-3}-1982.3 \mathrm{kgm}^{-3}$ green density and $2573.5 \mathrm{kgm}^{-3}$ $2435.0 \mathrm{kgm}^{-3}$ sintered density while for $0-40 \%$ silica sand they reported $2329.5 \mathrm{kgm}^{-3}-2010.2 \mathrm{kgm}^{-3}$ greendensity and $2573.5 \mathrm{kgm}^{-3}-2440.7 \mathrm{kgm}^{-3}$ sintered densities.

\subsection{Tensile Strength Test}

The results of the ultimate tensile strength (UTS), elongation and the Young modulus are as shown in Figures 5 and 6. Figure 5 shows the variations of UTS and elongation while variation of Young modulus of the produced composites with volume percentage BA addition is given in figure 6 .

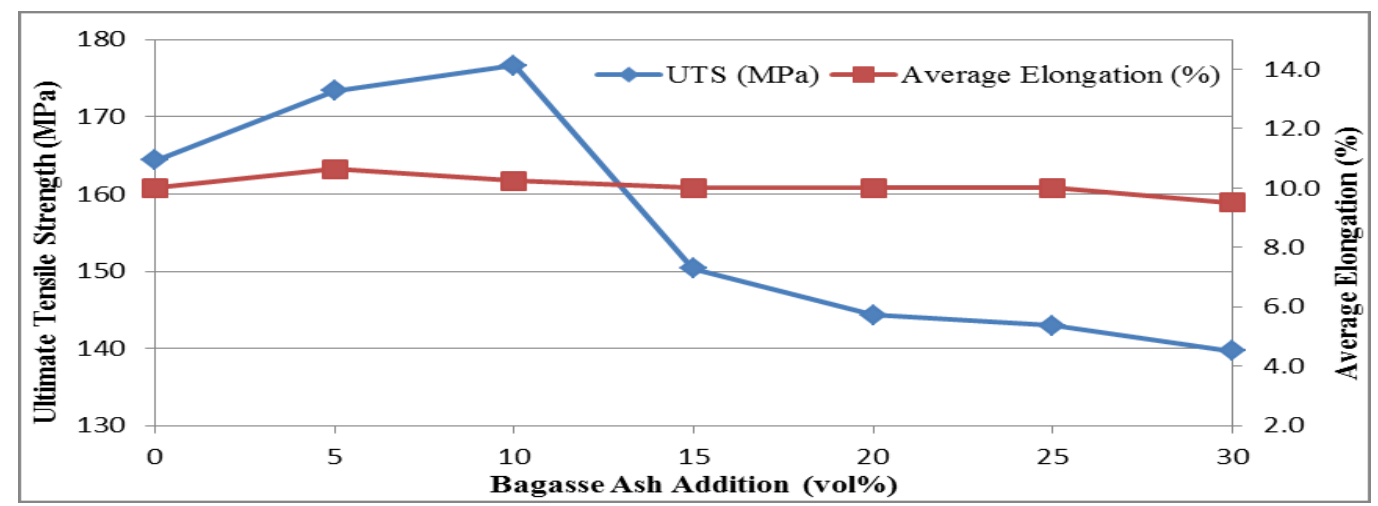

Figure 5: Variation of Ultimate Tensile Strength and Average Elongation with BA Addition

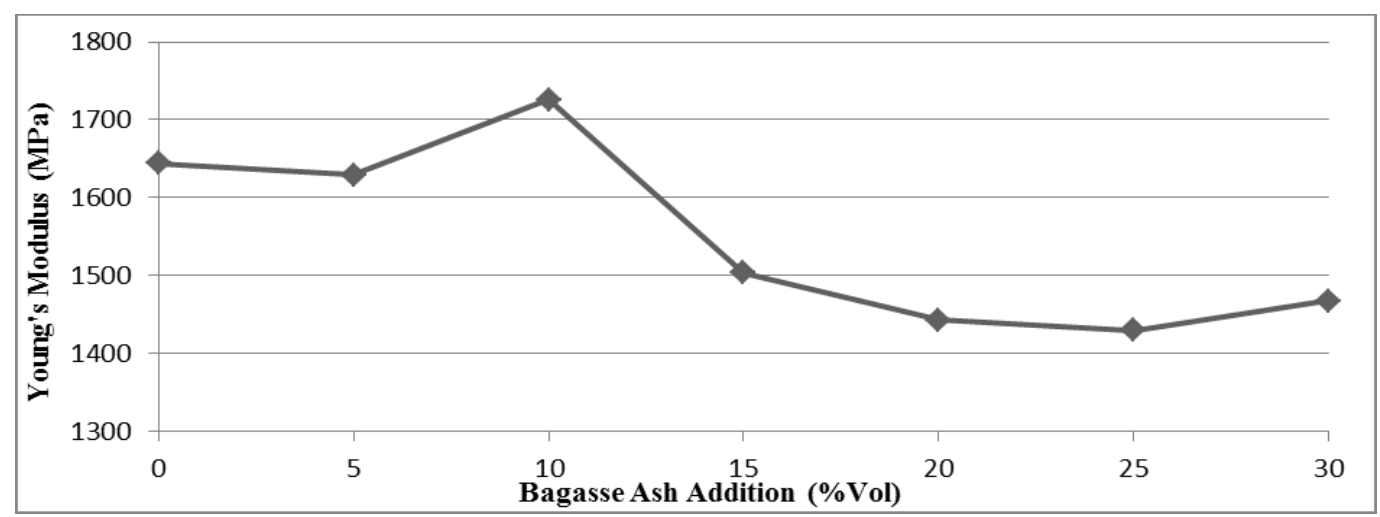

Figure 6: Variation of Young Modulus (E) with Bagasse Ash \% Addition

From Figure 5, the UTS of the produced composites by addition of BA initially increased from 164.374MPa for the control sample to $176.683 \mathrm{MPa}$ for $10 \% \mathrm{BA}$, the value decreased to $139.677 \mathrm{MPa}$ at $30 \%$ BA. This trend shows that there is improvement in the UTS up to 10vol\% BA and thereafter the UTS decreased with an increase in ash percentage above $10 \mathrm{vol} \%$ in the alloy. The percentage elongation of all the produced composites as shown in Figure 5, is approximately the same between $9.5 \%$ to $10.6 \%$. The results of Young modulus shown in Figure 6 also follow approximately the same trend as the UTS with maximum value at $10 \%$ BA addition. The UTS decreases because increasing ash introduces more reinforcements in the matrix and thereby produces more sites for crack initiation and hence lowers the load bearing capacity of the composites thus reducing the UTS [13]. Besides, if the number of contacts between $\mathrm{SiO}_{2}$ and $\mathrm{Al}_{2} \mathrm{O}_{3}$ particulates increases, then the particles are no longer isolated by the ductile aluminium alloy matrix. Therefore, cracks will not get arrested by the ductile matrix and would propagate easily between the silica and alumina particulates. Furthermore, the elastic stresses generated due to the thermal mismatch put the particles into compression and the matrix into tension. These residual stresses affect the material properties in and around the crack tips and the fracture toughness values would be altered. Consequently, these residual stresses would probably contribute to the brittle nature of composites [13]. Therefore, the maximum UTS is at $10 \mathrm{vol} \%$ BA with a value of 
176.683MPa. The results of UTS are in line with the results reported by Neelima et al. [14] who used silicon carbide as reinforcement in $\mathrm{Al}-\mathrm{SiC}$ composites and reported that UTS increased from $80.84 \mathrm{MPa}$ at $0 \%$ to $94.21 \mathrm{MPa}$ at $15 \%$ and decreased to $83.00 \mathrm{MPa}$ at $20 \%$ and Shanmughasundaram et al. [11] who reported an increase in UTS with fly ash as reinforcement from $77 \mathrm{MPa}$ at $0 \%$ to $118 \mathrm{MPa}$ at $15 \%$ and then a decrease to $104 \mathrm{MPa}$ at $25 \%$. The trend also supports the results in some other studies $[8,9]$ in which an increase in UTS from $278 \mathrm{MPa}$ at $0 \%$ to $313 \mathrm{MPa}$ at $8 \%$ RHA was reported.

\subsection{Impact Strength Test} figure 7.

The variation of the impact strength of the produced composites with vol $\%$ of BA addition is given in

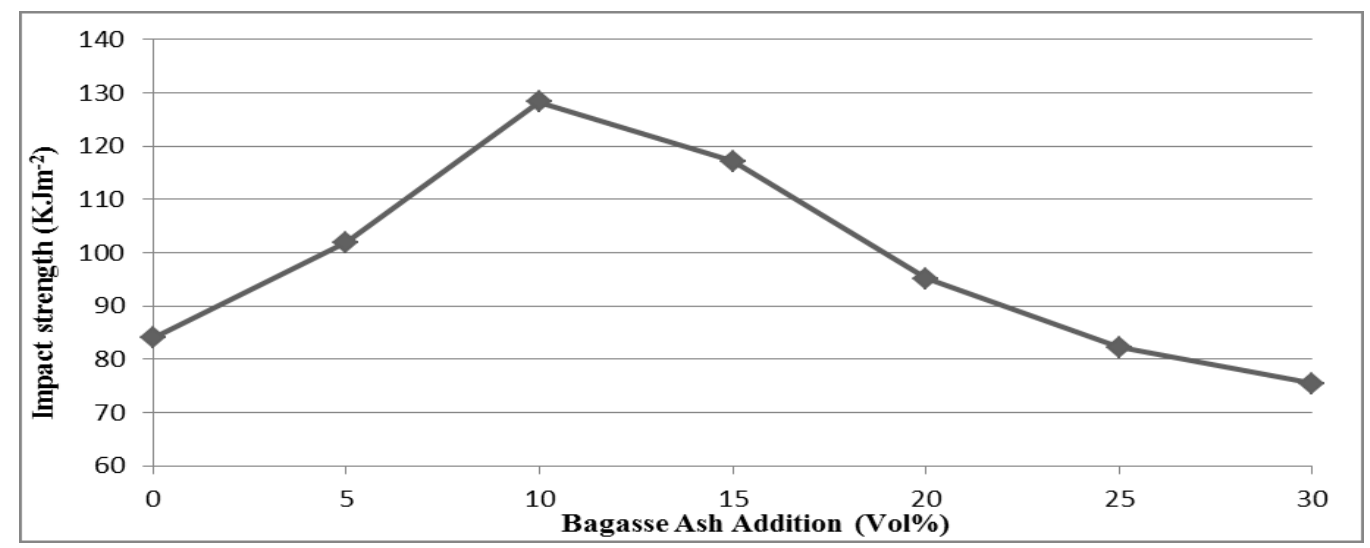

Figure 7: Variation of Impact Strength with BA Addition

Figure 7 shows that the impact strength of the composites increases from $84.020 \mathrm{Jm}^{-2}$ for control sample to $128.262 \mathrm{Jm}^{-2}$ at $10 \%$ ash and the composite has better impact property up to $20 \%$ ash addition with $95.092 \mathrm{Jm}^{-2}$. The maximum impact strength of $128.262 \mathrm{Jm}^{-2}$ was achieved at $10 \%$ ash. Literature reviewed does not give adequate information on the impact strength of composites used for production of automobile parts to enable comparison. However, the results show that there is a significant improvement in the impact strength of the produced composites as compared with the unreinforced aluminium alloy.

\subsection{Hardness Test}

The values of the Hardness Rockwell value (HRV) are shown in Figure 8.

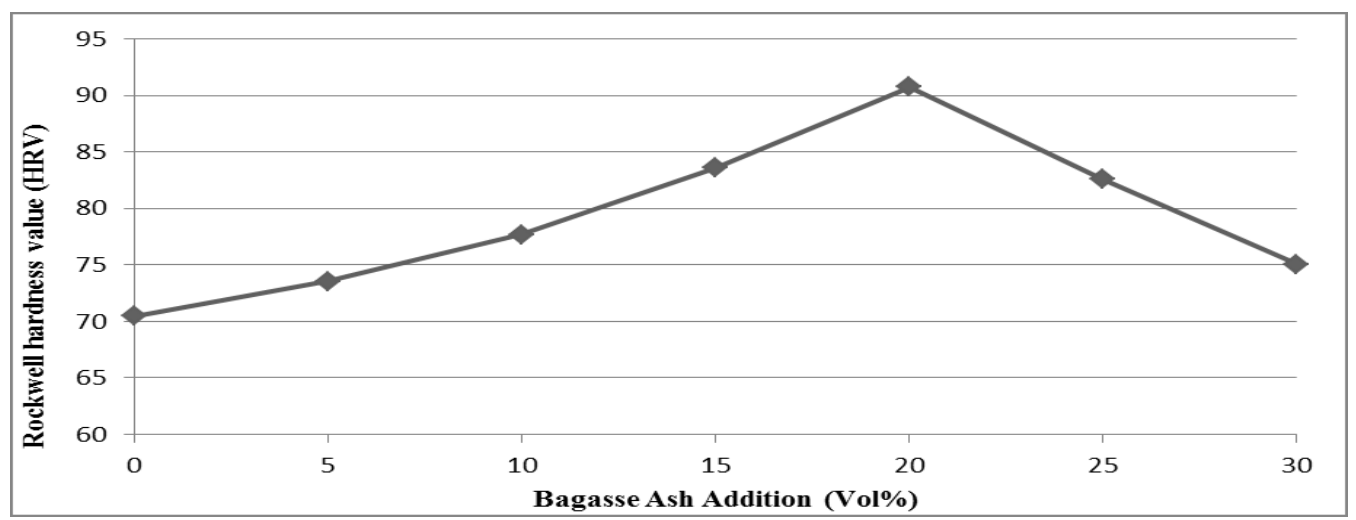

Figure 8: Variation of Rockwell Hardness Value with BA Addition

From Figure 8, it can be observed that the hardness of the produced composites increased approximately linearly with increase in BA addition from $70.467 \mathrm{HRV}$ for control sample to a maximum of $90.767 \mathrm{HRV}$ at $20 \mathrm{vol} \% \mathrm{BA}$ and then decreased to $75.067 \mathrm{HRV}$ at $30 \mathrm{vol} \%$ and thus all the composites specimens had higher HRV than the control specimen hence, the composites have better hardness property. The trend of the results supports many results in the literature. It supports the results reported in an earlier study [10] which reported an increase from $17 \mathrm{HRV}$ at $0 \%$ to $30 \mathrm{HRV}$ at $15 \%$ RHA and some other studies $[15,16,17]$ which obtained an increase from $35 \mathrm{HRV}$ at $0 \%$ to $48 \mathrm{HRV}$ at $10 \%$ BA. Luangvaranunt et al. [18] reported $17 \mathrm{HRV}$ at $0 \%$ RHA to $48 \mathrm{HRV}$ and $45 \mathrm{HRV}$ at $15 \%$ RHA for reacted area and as-aged hardness, Prasad and Krishna [8, 9] 
reported an increase in hardness from $68 \mathrm{BHN}$ at $0 \%$ RHA to $83 \mathrm{BHN}$ at $8 \%$ RHA and Shanmughasundaram et al. [11] used fly ash and obtained an increase from $19 \mathrm{BHN}$ at $0 \%$ to $51 \mathrm{BHN}$ at $20 \%$ and a decrease to $45 \mathrm{BHN}$ for $25 \%$.

\subsection{Fatigue Strength}

The variation of fatigue behaviour at constant load of $80 \mathrm{~N}$ with volume percentage BA addition is shown in Figure 9.

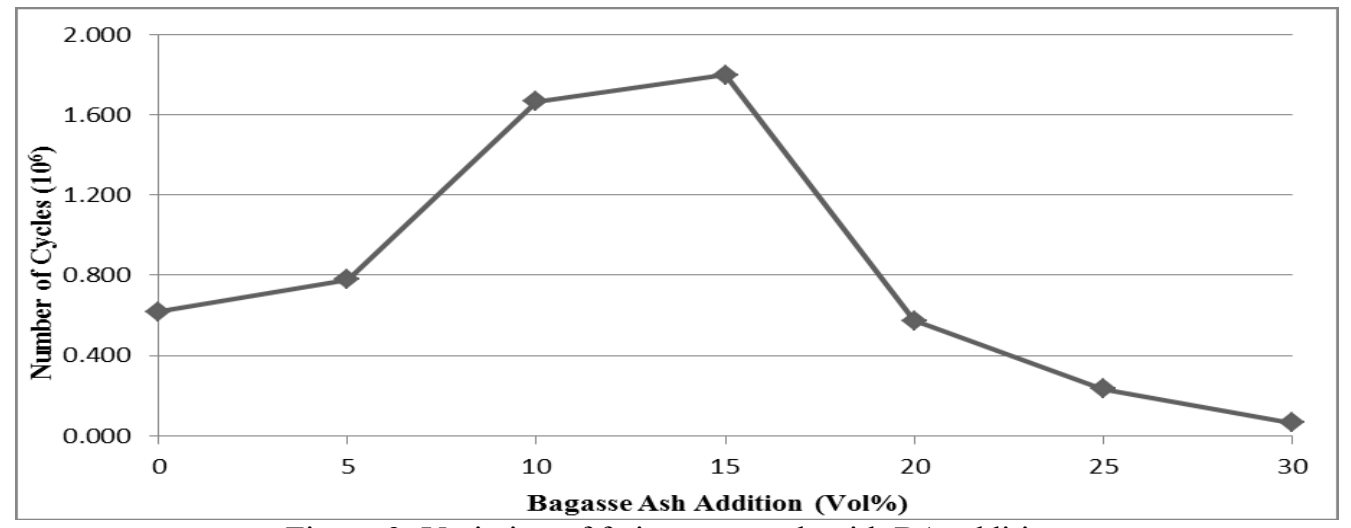

Figure 9: Variation of fatigue strength with BA addition

From Figure 9, the number of cycles increased from $0.620 \times 10^{6}$ for the control sample to $1.797 \times 10^{6}$ at $15 \% \mathrm{BA}$ and decreased to $0.066 \times 10^{6}$ at $30 \% \mathrm{BA}$. This implies that the fatigue strength of the composites increases with increase in ash addition up to $15 \%$ for BA and decreases with further addition up to $30 \%$. The particulate reinforced composites show improved fatigue behaviour compared to unreinforced alloy and such improvement is attributed to the higher stiffness reinforcement material in the composites. For a given matrix material, the stress concentration in a composite where the matrix is surrounded by high stiffness reinforcement particles, is lower than in the unreinforced alloy. Since more of the load is being carried by the high stiffness reinforcement particles in the composite, therefore the matrix material in the composites will be subjected to lower stress than similar matrix material in the unreinforced alloy $[19,20]$.

\subsection{Statistical Analysis}

Table 3 shows the results of analysis of variance among the means of density and mechanical properties test result for the composites.

Table 3: Statistical Analysis among the Means of Density and Mechanical Properties of BA composites

\begin{tabular}{|c|c|c|c|c|c|c|}
\hline Properties & Analysis & Sum of Squares & Degree of Freedom & F-Statistics & Significance & Remark \\
\hline Density & ANOVA & 591928.221 & 20 & 877.280 & 0.000 & $\mathrm{~S}$ \\
\hline \multirow{2}{*}{ UTS } & \multirow{2}{*}{ Robust Test } & --- & 6 and 6.093 & 42.679 & 0.000 & S \\
\hline & & --- & 6 and 6.279 & 33.345 & 0.000 & S \\
\hline$\%$ Elongation & ANOVA & 84.000 & 20 & 0.970 & 0.480 & NS \\
\hline Young modulus & ANOVA & 400042.553 & 20 & 3.791 & 0.019 & S \\
\hline Impact strength & ANOVA & 6985.775 & 20 & 218.416 & 0.000 & S \\
\hline Hardness & ANOVA & 890.810 & 20 & 140.490 & 0.000 & S \\
\hline Fatigue strength & ANOVA & $8.171 \times 10^{12}$ & 20 & 166.368 & 0.000 & $\mathrm{~S}$ \\
\hline
\end{tabular}

The results of the statistical analysis of the composites show that there is a significant difference among the means of each property of the composites of different levels of replacement of ashes $(\mathrm{P}<0.05)$ except for elongation where there is no significant difference $(\mathrm{P}>0.05)$. This implies that varying the proportion of $\mathrm{BA}$ in aluminium matrix within the range of $0-30 \mathrm{vol} \%$ significantly changes the density, UTS, Young modulus, impact strength, hardness and fatigue strength of the composites.

\section{Conclusions}

The following conclusions were made:

1. Bagasse ash is successfully incorporated in the aluminium alloy $(\mathrm{Al}-7 \% \mathrm{Si})$ at a temperature of $800^{\circ} \mathrm{C}$ by stirring method.

2. Incorporating bagasse ash in the aluminium alloy reduces its density to a minimum value of $2292.208 \mathrm{kgm}^{-3}$ at $30 \mathrm{vol} \%$.

3. Addition of BA in aluminium alloy to form a composite generally improves its mechanical properties. 
4. The maximum ultimate tensile strength and Young modulus reached were 176.683MPa and 1725.425MPa both at $10 \mathrm{vol} \%$ of BA.

5. The maximum impact strength reached was $128.262 \mathrm{kJm}^{-2}$ at $10 \mathrm{vol} \%$ BA and up to $20 \mathrm{vol} \%$ BA the composites have better impact strength than the control sample.

6. The maximum hardness strength reached was $90.767 \mathrm{HRV}$ at $20 \mathrm{vol} \% \mathrm{BA}$ and all the composites have better Rockwell hardness values compared to the control sample.

7. The maximum fatigue strength of $1.797 \times 10^{6}$ cycles at $15 \mathrm{vol} \% \mathrm{BA}$ wasobtained.

8. The obtained properties are within the range of properties of materials used in production of automobile components such as engine blocks, pistons etc.

\section{Recommendations}

1. Other methods of production such as powder metallurgy and melt infiltration should be used for production of Al-BA composites for comparison.

2. Other tests such as wear test, corrosion test, thermal and electrical conductivity test etc. should be conducted to fully characterise the composites.

3. X-ray diffraction test should be conducted on the ash to determine its crystability at various temperatures.

\section{Acknowledgement}

The authors will like to express their appreciations to Mechanical Engineering Department of Modibbo Adama University of Technology, Yola - Nigeria and Mechanical and Metallurgical Engineering departments of Ahmadu Bello University, Zaria - Nigeria for giving them access to their equipments.

References

[1]. W. M. Khairaldien, A. A. Khalil and M. R. Bayoumi. Production of Aluminium-Silicon Carbide Composites Using Powder Metallurgy at Sintering Temperature above Aluminium Melting Point. Journal of Material Science and Engineering, A399, $2005,822-831$.

[2]. N. Yoshikawa, Y. Nakano, K. Sato and S. Taniguchi. Fabrication of Composite Materials Using Aluminium Scrap and Wasted Glass. Material Transaction, 46(12), 2005, 2582-2585.

[3]. M. K. Surappa. Aluminium Matrix Composites: Challenges and Opportunities. Sadhana India, 28(1 and 2), 319-334, 2003.

[4]. P. Mallick. Fiber Reinforced Composites Materials, Manufacturing and Design. Boca Raton, FL. CRC Press, 2008.

[5]. G. K. Roy and B. Augustine. Recovery of Chemicals from Agricultural Residue-A Critical View. Journal of Institute of Engineers, 62(1), 1981, 36-41.

[6]. K. Katsuyoshi, O. Hideki, U. Junko and U. Takateru. Innovative Reuse of Agricultural Waste as Industrial Raw Material to Form Magnesium Composite. Material Transactions, 46(1), 2005, 2586-2591.

[7]. A. M. Usman, A. Raji, N. H. Waziri and M. A. Hassan.A Study on Silica and Alumina Potential of the Savannah Bagasse Ash,IOSR Journal of Mechanical and Civil Engineering. 11(3),Version 5,2014,48-52.

[8]. D. S. Prasad and A. R. Krishna. Fabrication and Characterization of A356.2-Rice Husk Ash Composite Using Stir Casting Technique.International Journal of Engineering Science and Technology, 2(12), 2010, 7603-7608.

[9]. D. S. Prasad and A. R. Krishna. Production and Mechanical Properties of A356.2 RHA Composites. International Journal of Advanced Science and Technology, 33, 2011, 51-58.

[10]. C. Dhadsanadhep, T. Luangvaranunt, J. Umeda and K. Kondoh. Fabrication of $\mathrm{Al}_{1} / \mathrm{Al}_{2} \mathrm{O}_{3}$ Composite by Powder Metallurgy Method from Aluminum and Rice Husk Ash. Journal of Metals, Materials and Minerals, 18(2), 2008, 99-102.

[11]. P. Shanmughasundaram, R. Subramanidan and G. Prabhu. Some Studies on Aluminium - Fly Ash Composites Fabricated by Two Step Stir Casting Method. European Journal of Scientific Research, 63(2), 2011, 204-218.

[12]. H. Zuhailawati, P. Samayamutthirian and C. H. Mohd Haizu. Fabrication of Low Cost Aluminium Matrix Composite Reinforced With Silica Sand. Journal of Physical Sciences, 18(1), 2007, 47-55.

[13]. A. M. S. Hamouda, S. Sulaiman, T. R. Vijayaram, M. Sayuti and M. H. M. Ahmad. Processing and Characterisation of Particulate Reinforced Aluminium Silicon Matrix Composite. Journal of Achievements in Materials and Manufacturing Engineering, 25(2), 2007, 11-16.

[14]. D. C. Neelima, V. Mahesh and N. Selvaraj. Mechanical Characterization of Aluminium Silicon Carbide Composite. International Journal of Applied Engineering Research, 1(4), 2011, 793-799.

[15]. V. S. Aigbodion, S. B. Hassan, E. T. Dauda and R. A. Mohammed. The Development of Mathematical Model for the Prediction of Ageing Behaviour for Al-Cu-Mg/Bagasse Ash Particulate Composites. Journal of Minerals \& Materials Characterization \& Engineering, 9(10), 2010, 907-917.

[16]. V. S. Aigbodion, S. B. Hassan, G. B. Nyior and T. Ause. Potential Utilization of Solid Waste Bagasse Ash. Journal of Minerals \& Materials Characterization \& Engineering, 9(1), 2010, 67-77.

[17]. V. S. Aigbodion, S. B. Hassan, E. T. Dauda and R. A. Mohammed. Experimental Study of Ageing Behaviour of Al-CuMg/Bagasse Ash Particulate Composites. Tribology in Industry, 33(1), 2011, 28-35.

[18]. T. Luangvaranunt, C. Dhadsanadhep, J. Umeda, E. Nisaratanaporn and K. Kondoh. Aluminum-4 mass\%Copper/Alumina Composites Produced from Aluminum Copper and Rice Husk Ash Silica Powders by Powder Forging. Materials Transactions, 51(4), 2010, 756-761.

[19]. R. Donahue and P. A. Fabiyi. Manufacturing Feasibility of All-Aluminum Automotive Engines Via Application of High Silicon Aluminum Alloy. Society of Automotive Engineers, Inc, NY, 2000.

K. K. Chawla and N. Chawla. Metal Matrix Composites. Boston: Kluwer Academic Publishers, 2004. 